\title{
Centenário da doença de Chagas
}

\section{Chagas disease centenary}

São Paulo, 19 de dezembro de 2008.

Prezados editores

Em 1909, iniciaram-se os conhecimentos sobre a doença de Chagas, expressiva endemia rural em vários países latino-americanos. Na ocasião, o cientista brasileiro Carlos Chagas efetuou investigações científicas, até hoje sem similares, devendo-se a relevância de tais pesquisas ao fato meritório desse médico ter desvendado, sem os recursos tecnológicos disponíveis atualmente, e, individualmente, destacar os fundamentos de uma enfermidade: evidenciou pela primeira vez a existência de protozoário que ganhou a designação de Trypanosoma cruzi; em homenagem a Oswaldo Cruz, companheiro de trabalho em instituição de pesquisas; revelou que esse parasita infecta pessoas por meio das fezes de inseto triatomíneo, que se alimenta exclusivamente de sangue e tem diversas denominações populares, como “barbeiro”, além de outras; comprovou que o protozoário citado causa enfermidade infecciosa em seres humanos; e ainda, encontrou pelo menos um reservatório silvestre do tripanossomo. Tantos esclarecimentos advieram, inusitadamente, da competência de um só estudioso, que pelo feito recebeu significativo prêmio internacional.

É simples compreender porque o mal é rotulado como doença de Chagas.

Diante do sucedido, surgiu preocupação no âmbito da saúde pública e também da comunidade, em geral. Contudo, apareceu um contratempo, o escritor e sanitarista Afranio Peixoto liderou opinião segundo a qual essa moléstia não era importante e não causaria os problemas antevistos e temidos. Por isso, o assunto chegou a "esfriar". Logicamente, o famoso literato e adeptos estavam errados.

Não é cabível esquecer que Salvador Mazza, da Missão de Estudos de Patologia Regional Argentina, e Rodolfo Talice, no Uruguai, apontaram muitos aspectos da enfermidade, respaldando a convicção de que a doença de Chagas exigia cuidados, esclarecimentos e enfrentamento. Lembramo-nos de caracterização emitida por Talice: a doença de Chagas revela as péssimas condições nas quais vive grande parte da população de países latino-americanos.
O mérito de Carlos Chagas é, sem dúvida, de grande porte. Dois detalhes, no entanto, geraram indecisão: a inclusão de tireopatia e neuropatia no conjunto de danos causados pela infecção. Possivelmente investigações conduzidas em locais onde esses danos eram comuns originaram associação com a parasitose. Tudo está esclarecido e essas notícias configuram singularidades irrelevantes. Não esqueçamos que inexistiam os recursos que sobrevieram.

Avaliações de diversificadas maneiras, sobretudo epidemiológicas, identificaram o triste significado da doença, mostrando elevados números de acometidos, até mesmo de forma grave. Mazza muito contribuiu para desmistificar a insustentável crença de contestadores. Excelentes caracterizações ficaram consolidadas, nos setores da etiologia, da epidemiologia, da clínica, do diagnóstico, da divulgação e dos cuidados assistenciais cabíveis ou disponíveis. Tudo isso em coerência de profissionais vinculados à elucidação de um conjunto de aspectos.

Hábeis, capazes e dignos pesquisadores continuaram a investigar intensamente a proeminente parasitose. É provável que não sejamos plenamente justos; porém, os citados representam a plêiade de todos os ilustres colaboradores. Assim sendo, citamos Aluízio Prata, Amilcar Vianna Martins, Anis Rassi, Antonio Walter Ferreira, Astolfo Ferraz de Siqueira, Edison Reis Lopes, Emmanoel Dias, Eurico Vilela, Evandro Chagas, Fritz Köberle, Francisco Ferrioli Filho, Humberto de Oliveira Ferreira, João Carlos Pinto Dias, Joffre Marcondes de Rezende, José Lima Pedreira de Freitas, José Rodrigues Coura, Maria Aparecida Shikanai Yasuda, Mario Endsfeld Camargo, Masayuki Okumura, Oswaldo Paulo Forattini, Ricardo Ribeiro dos Santos, Sonia Gumes Andrade, Thales de Brito, Vanize de Oliveira Macêdo, Zigman Brener e Zilton de Araújo Andrade, entre outros.

A sempre desejada prevenção nunca esteve esquecida. Propostas surgiram e só há pouco ocorreu marcante sucesso. Cuidadosa programação, vontade política, bom aporte de recursos e excelente coordenação de João Carlos Pinto Dias propiciaram a interrupção da veiculação rotulada como vetorial do tripanossomo, sendo reconhecida pela Organização Pan-Americana de Saúde/Organização Mundial de Saúde. 
O "barbeiro" multiplica-se em casas rudimentares, ditas de pau-a-pique ou de adobe. São moradias apropriadas para os insetos e não para pessoas. O combate ao vetor devidamente executado e, paralelamente, a melhoria do panorama agrário diminuíram as impropriedades habitacionais, resultando em erradicação do barbeiro no País.

Agora, precisa persistir ampla e eficaz vigilância epidemiológica, com atenção permanente. É temida a vinda de barbeiros silvestres e insidiosa ocupação de áreas livres desse inseto. De passagem anotamos atenção atual para a presença do mal na Amazônia, assunto antes pouco focalizado. Ainda mais: transmissões qualificadas como excepcionais e que, acreditamos, seria melhor considerá-las alternativas, apesar de valorizadas com ênfases diferentes, eram componentes não compatíveis com a atuação dos insetos. Verificações cada vez mais comuns estão dando elevadas proporções a elas. Tais tipo são: congênito; transfusional; acidente de laboratório; e os motivados por transplantes de órgãos; leite materno e contaminação por via oral. Sem dúvida, é urgente demarcar as medidas profiláticas pertinentes.

No Brasil, no momento, há cerca de 2.500.000 indivíduos infectados pelo Trypanosoma cruzi. Os acometimentos são de intensidades diversas. Há necessidade de prever assistência médica adequada, abrangendo acolhimento, instruções e uso de medidas possíveis, segundo o que terapeuticamente é correto para cada caso. Em 1978-1983, estimativa que dependeu de inquérito bem construído demarcou um número em torno de 5.500.000. A diminuição dependeu de motivos diversos e, também da mortalidade atinente à doença de Chagas. Logicamente, a cifra sofrerá redução, coerente com a profilaxia concretizada.

Sucedeu o advento de profunda e louvável caracterização da enfermidade. Todavia, no centésimo aniversário lamentamos a ausência de três progressos. Primeiro: não se conseguiu explicação cabal sobre a etiopatogenia, que explicaria como o parasita lesa o organismo; se plenamente esclarecido isso, sobrevirão benefícios ambicionados. Segundo: não temos prova sorológica totalmente fiel, pois não contamos com alguma infalível, a despeito da existência de numerosas bastante úteis. O derradeiro: a falha a respeito da conquista de auxílio, medicamentosos ou não, apto a eliminar o agente causal dos infectados; desde os anos 1940 conhecemos pesquisas ligadas à essa questão e atualmente contamos só com dois fármacos, insuficientes para estamos perto do ideal.

A doença de Chagas figura como negligenciada nas intenções de indústrias farmacêuticas, programas assistenciais, núcleos universitários e órgãos financiadores, quando a cura é desiderato máximo. A doença de Chagas e outras endemias presentes no Brasil são descuradas por empresas farmacêuticas e por sedes de pesquisas internacionais. Não rendem como assuntos preferidos diante de lucros. Ganhar materialmente predomina sobre proveito para a saúde pública e, conseqüentemente, para “gentes”. Situações em vizinhos sul-americanos divergem do que está sendo conseguido aqui. Almejamos que eles não esmoreçam.

Instrumentos financiadores de pesquisas, reconheçamos, ajudaram bastante investigadores brasileiros. Disso advieram colaborações meritórias. Sugerimos, no entanto, que os estudos tenham objetividade e dêem primazia para projetos que visem avanços necessários e não representem apenas troféus em concursos públicos e universitários.

Vacina ou algo congênere para conceder proteção imunitária contra a infecção figuraram comumente como desejos. Tentativas para conseguir resolução aceitável não superaram utopias. Uma ponderação tem sentido nesse tópico: julgamos que no Brasil, presentemente, não há espaço para emprego desses expedientes. Nos demais países latino-americanos enfoques podem diferir do que ponderamos.

Finalizando, exaltamos o exemplar e esplêndido feito de Carlos Chagas e louvamos as posteriores verificações científico-assistenciais, algo lentas, mas profícuas. Resta almejar que se concretizem mais progressos, em especial quanto a particularidades ainda não superadas.

Vicente Amato Neto

Faculdade de Medicina da Universidade de São Paulo amatonet@usp.br

Jacyr Pasternak

Hospital Israelita Albert Einstein 